\title{
Transcranial Doppler ultrasound in the ICU: it is not all sunshine and rainbows
}

\author{
Pablo Blanco ${ }^{1 *}$ and Anselmo Abdo-Cuza ${ }^{2}$
}

Dear Editor,

We read the article about Transcranial Doppler (TCD) for intensivists [1]. Although not a novel ultrasound technique, in particular the "blind" o non-imaging TCD (bTCD), authors' efforts to promote some basic applications of the Duplex technique (transcranial color-coded duplex sonography, TCCS) are remarkable.

However, some technical points and assertions are dubious and/or incorrect, as noted below:

In the first place, regarding the midline shift (MLS) measurement technique by TCCS, (A-B)/2 is well-studied and validated against $C T$ [2]. While proposed by authors' as an "internal standard" [1], as shown in Fig. 1 of the original article [1], measuring the distance to the contralateral cranial bone is not described in the original technique, it is unnecessary and adds complexity; thus, it should not be taken into account, as is the case with the mentioned " $\mathrm{C}$ and $\mathrm{D}$ " technique. To the authors' knowledge, whether methodologically correct or not, there are no study validating either of them. Practitioners should be aware that the MLS measurement by TCCS is not reliable in the presence of bone defects (like decompressive craniectomy or skull fractures), temporal cephalohematoma, or changes in intracranial anatomy secondary to trauma [3], citing the most common examples observed in daily practice. Particularly in patients with a decompressive craniectomy, an alternative MLS measurement technique is well validated against CT [4].

Second, when moving from a bTCD technique to the Duplex technique, practitioners must be aware of the "mean velocities" recorded by the ultrasound machine: time-averaged maximum velocity, known as TAMAX or TAP and time-averaged mean velocity, also known as

\footnotetext{
*Correspondence: ohtusabes@gmail.com

1 Ecodiagnóstico-Centro de Diagnóstico por Imágenes, 3272, 50 St., Necochea 7630, Argentina

Full list of author information is available at the end of the article
}

TAMEAN or TAMV. While both are "mean" velocities, TAMEAN is approximately half the TAMAX [5]. Since in TCCS, the velocity considered is the TAMAX [5], using TAMEAN instead of TAP leads to underestimating velocities. This is clearly evidenced in Fig. 2 [1], where in the TCCS image, TAP is correctly used, but in the transcervical insonation, TAMV is used instead of TAP. Indeed, TAP should be compared when the Lindegaard Index (LI) is used, but comparing TAMAX/TAMEAN as is performed in Fig. 2 is an obvious mistake and readers need to be cautioned from making the same error. The actual LI in this case is 2.1, which indicates hyperemia (Fig. 1). According to this now well-performed TCD ratio, the angiographic finding of vasospasm was fortuitous, at least if this index is used independently [6]. In addition, transcervical insonation should be performed with the same phased-array probe to observe the "distal" extracranial internal carotid artery (ICA)-TAP (Fig. 2a) [7]. It should be noted that this segment is not assessed with the linear probe as shown in Fig. $2 c$ of the original article. In addition, large correction angles $\left(60^{\circ}\right)$ result when a linear transducer is used and this must be especially avoided when comparing middle cerebral artery (MCA)/ ICA TAP. Thus, the Doppler correction angle should not be used [8]. As noted, transcervical insonation should be a basic part of point-of-care ultrasound (POCUS)-TCD, at least if vasospasm evaluation is considered.

Third, to the best of our knowledge, we are not aware of any guidelines that recommend TCD as a screening tool for further indication of an ancillary test to confirm the diagnosis of brain death. When determining the presence of cerebral circulatory arrest (CCA), many countries around the world accept this tool as an ancillary test to confirm the clinical diagnosis of brain death [9]. For example, there are formal TCD guidelines in Latin-American addressing this issue $[10,11]$. For this indication, accepted TCD-CCA criteria for both "anterior" and "posterior" cerebral arterial circulation must be 


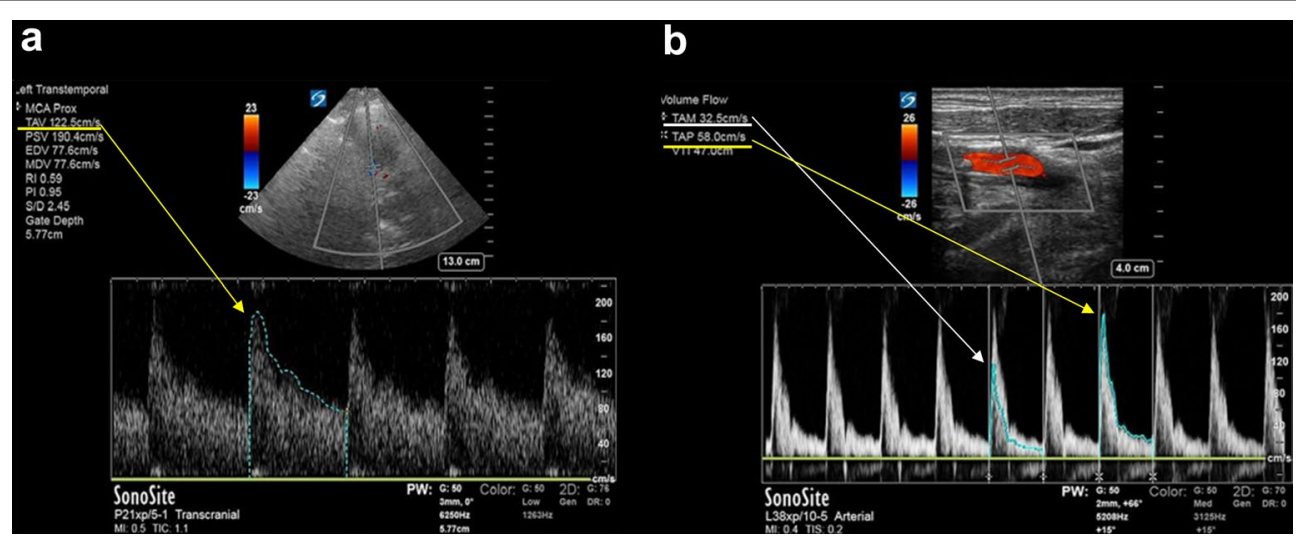

Fig. 1 (corresponding to b and c of Fig. 2 [1]). Note the different and confusing nomenclature regarding "mean velocities". As depicted from the trace of the envelope of the Doppler spectra (yellow arrows), time-averaged maximum velocity is recorded, namely, TAV (time-averaged velocity) in (a) and TAP (time-averaged peak velocity) in (b). There is also no doubt in a that is TAP, because pulsatility index (PI) is calculated using this value [peak systolic velocity (PSV)-end-diastolic velocity (EDV)/TAV]. Time-averaged mean velocity is not recorded in (a), but is shown in (b) as TAM, traced in the middle of the Doppler spectra (white arrow). In TCCS, time-averaged maximum or peak velocities are the "mean" velocities that should be considered. The correct Lindegaard Index (Middle cerebral artery TAP/internal carotid artery TAP) in this case is 123/58, equal to 2.1 (corresponding to hyperemia if considered independently). It is thus clearly incorrect to use different "mean velocities" when calculating the LI, such as TAP/TAMEAN. Note: the waveform in (b) is consistent with an external carotid artery flow, given its sharp systolic upstroke, high-resistance velocity profile, and early diastolic notch (another mistake that should be taken into account)

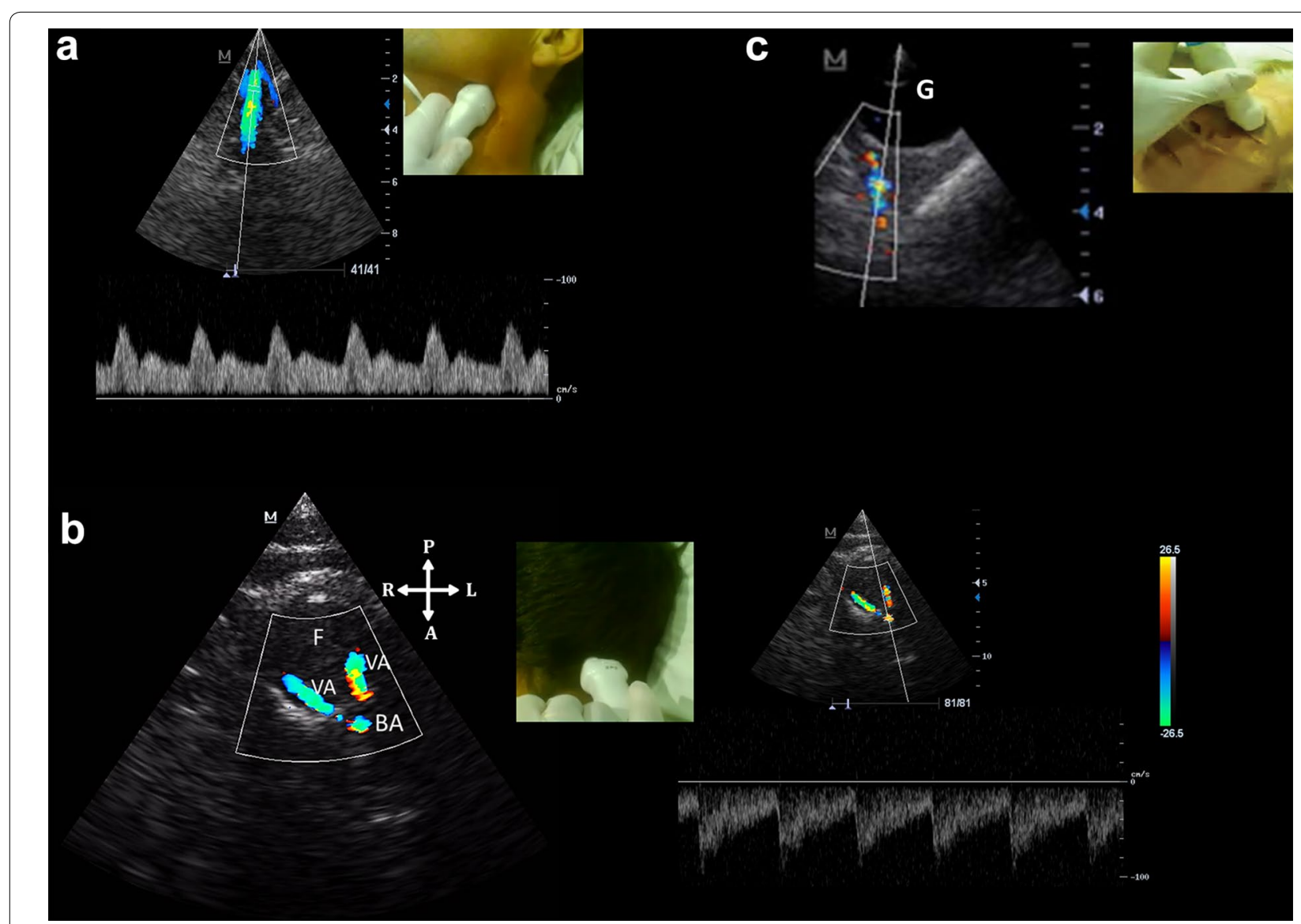

Fig. 2 a Transcervical window, phased-array probe. Note that the distal internal carotid artery is insonated and that angle correction is not needed in pulsed-wave Doppler. b Transforaminal window, phased-array probe. Note the inverted $V$ configuration of the posterior circulation on color Doppler imaging (coded blue, indicating that blood is moving away from the transducer), depicted by both vertebral arteries (VA) and the basilar artery (BA), showing also the corresponding spectral Doppler on the inferior channel. F: foramen magnum; VA vertebral artery; BA basilar artery. c Transorbital window, phased-array probe. G: ocular globe 


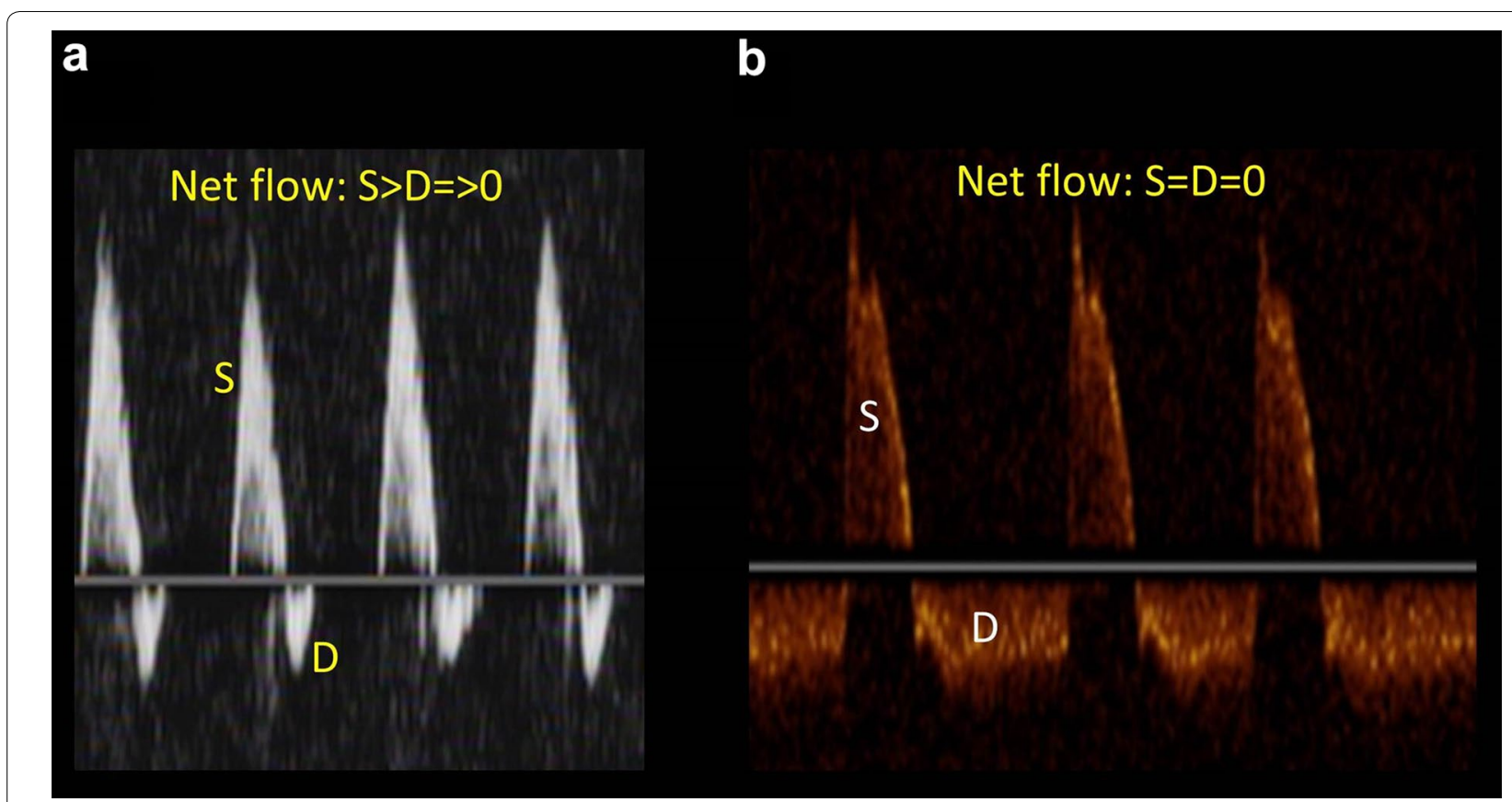

Fig. 3 a High-resistance biphasic flow, with a net forward flow, not compatible with cerebral circulatory arrest. b Oscillating flow, with a net flow of 0 , corresponding to cerebral circulatory arrest. $S$ systole; $D$ diastole

registered [12, 13]. Thus, intuitively, the transtemporal window is not enough for this indication. As a point-ofcare application, transforaminal window should also be considered a basic window, at least if a CCA application is proposed (Fig. 2b). Transorbital (Fig. 2c) and transcervical (Fig. 2a) are also useful (although not fully accepted) in some actual patients to determine CCA, in particular when intracranial arterial flows are not detected on first examination, due to inadequate bone insonation windows, for example (observed in at least $25 \%$ of the patients) [13]. Regarding Doppler CCA criteria, the oscillating flow, although a biphasic flow, needs to be clearly differentiated from a high-resistance biphasic flow with a net forward flow (Fig. 3). In doubtful cases, always correlating with the clinical signs of brain death, modifications of the waveforms with interventions, such as osmotic therapy, may allow practitioners to discard the CCA diagnosis given the reversibility of the case on follow-up examinations.
Finally, velocities and indices (e.g., pulsatility index) are highly variable, resulting from physiologic (arousal, for example) to pathologic conditions (e.g., raising intracranial pressure) (Tables 1 and 2). Thus, caution should be exercised when interpreting TCD findings, which should always be considered within a multimodality monitoring, and not in isolation. The phrase "trends are your friend" is highly applicable when interpreting TCD velocities and indices.

In conclusion, POCUS TCD is not a perfect technique. Many aspects (technical and interpretative) should be considered to obtain a reliable TCD exam. In addition, for the reasons explained above, TCCS should not be limited to transtemporal windows, since transforaminal, transcervical, and transorbital windows have a defined role in basic TCD applications. The entire TCCS exam is performed with the same phased-array probe, based on the simplicity of POCUS, without the need of formal TCD examinations or dedicated machines, as happens 


\section{Table 1 Physiologic and pathologic conditions that can modify TCCS flow velocities [3]}

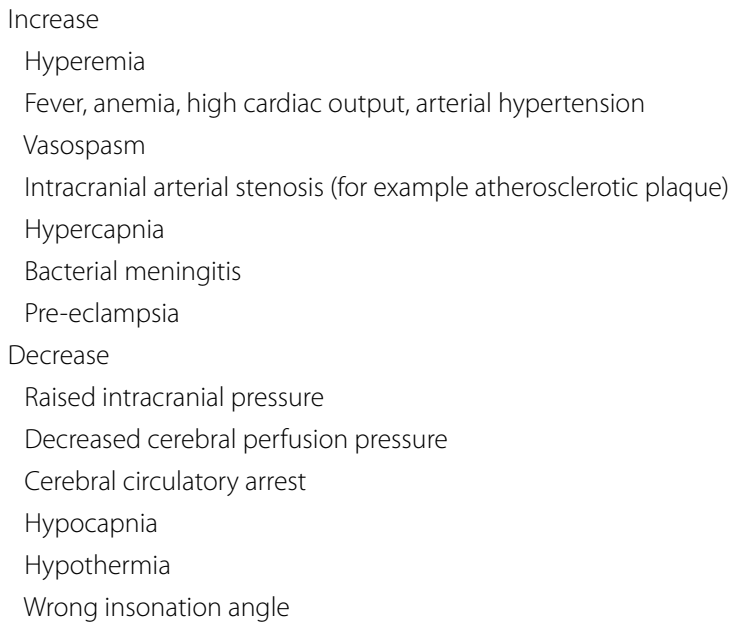

\section{Table 2 Physiologic and pathologic conditions that can modify TCCS Doppler indices [3]}

\author{
Increase \\ Raised intracranial pressure \\ Decreased cerebral perfusion pressure \\ Hypocapnia \\ Hypothermia \\ Cerebral circulatory arrest \\ Hyperviscosity \\ Intracranial artery occlusion \\ Advanced age (vessel stiffness) \\ Decrease \\ Hyperemia \\ Anemia, fever, high cardiac output, arterial hypertension \\ Hypercapnia \\ Vasospasm \\ Intracranial artery stenosis \\ Arteriovenous malformation \\ Rewarming following hypothermia
}

with most (if not all) POCUS applications in the ICU. It is clear that a TCD-training curricula is mandatory to fulfill intensivists' needs.

\section{Abbreviations}

TCD: transcranial Doppler; bTCD: blind or non-imaging TCD; TCCS: transcranial color-coded duplex sonography; MLS: midline shift; TAMAX/TAP: timeaveraged maximum velocity/time-averaged peak velocity; TAMEAN/TAMV: time-averaged mean velocity; LI: Lindegaard Index; CCA: cerebral circulatory arrest; POCUS: point-of-care ultrasound; CT: computed tomography.

\section{Authors' contributions}

PB and AAC contributed equally to this work. Both authors read and approved the final manuscript

\section{Author details}

1 Ecodiagnóstico-Centro de Diagnóstico por Imágenes, 3272, 50 St., Necochea 7630, Argentina. ${ }^{2}$ Centro de Investigaciones Médico-Quirúrgicas, 11-13 and 216 St., Siboney, La Habana 12100, Cuba.

\section{Acknowledgements}

Authors would like to thank Mrs. Julieta Vigna for the language guidance.

\section{Competing interests}

The authors declare that they have no competing interests.

\section{Ethics approval and consent to participate}

Not applicable.

Funding

None.

\section{Publisher's Note}

Springer Nature remains neutral with regard to jurisdictional claims in published maps and institutional affiliations.

Received: 31 October 2017 Accepted: 9 January 2018

Published online: 16 January 2018

\section{References}

1. Lau Vl, Arntfield RT (2017) Point-of-care transcranial Doppler by intensivists. Crit Ultrasound J 9:21

2. Seidel G, Gerriets T, Kaps M, Missler U (1996) Dislocation of the third ventricle due to space-occupying stroke evaluated by transcranial duplex sonography. J Neuroimaging 6(4):227-230

3. Blanco P, Blaivas M (2017) Applications of transcranial color-coded sonography in the emergency department. J Ultrasound Med 36(6):1251-1266

4. Caricato A, Mignani V, Bocci MG, Pennisi MA, Sandroni C, Tersali A, Antonaci A, de Waure C, Antonelli M (2012) Usefulness of transcranial echography in patients with decompressive craniectomy: a comparison with computed tomography scan. Crit Care Med 40(6):1745-1752

5. Blanco P (2015) Volumetric blood flow measurement using Doppler ultrasound: concerns about the technique. J Ultrasound 18(2):201-204

6. Gonzalez NR, Boscardin WJ, Glenn T, Vinuela F, Martin NA (2007) Vasospasm probability index: a combination of transcranial doppler velocities, cerebral blood flow, and clinical risk factors to predict cerebral vasospasm after aneurysmal subarachnoid hemorrhage. J Neurosurg 107(6):1101-1112

7. Alexandrov AV, Sloan MA, Wong LK, Douville C, Razumovsky AY, Koroshetz WJ, Kaps M, Tegeler CH, American Society of Neuroimaging Practice Guidelines Committee (2007) Practice standards for transcranial Doppler ultrasound: part I—test performance. J Neuroimaging 17(1):11-18

8. ACR-AIUM-SPR-SRU. Practice parameter for the performance of a transcranial Doppler ultrasound examination for adults and children (Revised 2017). http://www.aium.org/resources/guidelines/transcranial. pdf. Accessed 10 Dec 2017

9. Citerio G, Crippa IA, Bronco A, Vargiolu A, Smith M (2014) Variability in brain death determination in Europe: looking for a solution. Neurocrit Care 21(3):376-382

10. Lange MC, Zétola VH, Miranda-Alves M, Moro CH, Silvado CE, Rodrigues DL, Gregorio EG, Silva GS, Oliveira-Filho J, Perdatella MT, Pontes-Neto OM, Fábio SR, Avelar WM, Freitas GR, Task Force Group of the Neurosonology Department, Braz Acad Neurol (2012) Brazilian guidelines for the application of transcranial ultrasound as a diagnostic test for the confirmation of brain death. Arq Neuropsiquiatr 70(5):373-380 
11. Consensus Group on Transcranial Doppler in Diagnosis of Brain Death (2014) Latin American consensus on the use of transcranial Doppler in the diagnosis of brain death. Rev Bras Ter Intensiva 26(3):240-252

12. Ducrocq $X$, Hassler W, Moritake K, Newell DW, von Reutern GM, Shiogai T, Smith RR (1998) Consensus opinion on diagnosis of cerebral circulatory arrest using Doppler-sonography: Task Force Group on cerebral death of the Neurosonology Research Group of the World Federation of Neurology. J Neurol Sci 159(2):145-150
13. Naqvi J, Yap KH, Ahmad G, Ghosh J (2013) Transcranial Doppler ultrasound: a review of the physical principles and major applications in critical care. Int J Vasc Med 2013:629378

\section{Submit your manuscript to a SpringerOpen ${ }^{\circ}$ journal and benefit from:}

- Convenient online submission

- Rigorous peer review

- Open access: articles freely available online

- High visibility within the field

- Retaining the copyright to your article

Submit your next manuscript at $\boldsymbol{\nabla}$ springeropen.com 